\title{
ACHILLEA MILLEFOLLIUM - ASTERACEAE: ESTUDO FITOQUÍMICO, ESPECTROFOTOMÉTRICO E DA ATIVIDADE ANTIFÚNGICA (COLLETOTRICHUM MUSAE)
}

Achillea millefolium - Asteraceae: Phytochemical, antifungal activity (Colletotrichum musae) and spectrophotometric study

Rodrigo L. Peres ${ }^{1,2}$, Suzana C. S. Moraes ${ }^{1,3}$, Camilo A. de Carvalho ${ }^{4,5}$,

Paulo C. do Nascimento ${ }^{6,7}$, Leandro M. de Carvalho6,7, Marcelo B. da Silva ${ }^{8,9}$, Pabulo H. Rampelotto $^{10,11}$,Marcelo B. da Rosa ${ }^{12,13}$

${ }^{1}$ Universidade Vale do Rio Doce, 35020-220, Governador Valadares, MG, Brasil.

${ }^{2}$ Pesquisador do Laboratório de Química

${ }^{3}$ Mestranda no Programa de Pós-graduação em Imunopatologia das Doenças Infecciosas e

Parasitárias

${ }^{4}$ Departamento de Biologia Geral, Universidade Federal de Viçosa, 36570-000, Viçosa-MG, Brasil.

${ }^{5}$ Mestrando em Biologia Celular e Estrutural

${ }^{6}$ Departamento de Química, Universidade Federal de Santa Maria, 97110-970, Santa Maria-RS, Brasil.

7 Professor de Química Analítica

${ }^{8}$ Departamento de Ciências da Saúde, Biológicas e Agrária, Universidade Federal do Espírito Santo São Mateus, 29931-220, Espírito Santo-ES, Brasil.

${ }^{9}$ Pesquisador do Laboratório de Fitopatologia

${ }^{10}$ Departamento de Biologia, Universidade Federal de Santa Maria, 97110-970, Santa Maria-RS, Brasil.

${ }^{11}$ Acadêmico do Curso de Ciências Biológicas

12 Universidade Federal do Pampa - Campus Bagé, 96412-420, Bagé-RS, Brasil.

${ }^{13}$ Professor de Química

Recebido em 11/02/2009 - Aceito em 24/06/2009

*Autor para correspondência: marcelo.rosa@unipampa.edu.br

RESUMO: A Achillea millefolium (Asteraceae) é conhecida na medicina popular como mil-folhas, milem-rama, erva-de-carpinteiro e salvação-do-mundo. Suas aplicações fitoterápicas se devem as suas ações anti-inflamatória, antibacteriana, anti-hemorrágica, antidiarréica, antioxidante, antiedematosa 
osa, M. B. et al./Revista Eletrônica de Farmácia Vol 6(3), 81-93, 2009.

e cicatrizante. Neste trabalho, uma prospecção fitoquímica, assim como um estudo da atividade antifúngica envolvendo Colletotrichum musae e uma abordagem espectrofotométrica no estudo da extração da $A$. millefolium usando solventes de diferentes polaridades foram realizadas. Os resultados da prospecção fitoquímica revelaram a presença de flavonóides, taninos e cumarinas. A atividade antifúngica foi evidenciada frente ao patógeno Colletotrichum musae, onde cerca de $55 \%$ de seu crescimento foi inibido usando-se o extrato etanólico da $A$. millefolium. Um estudo espectrofotométrico envolvendo o perfil espectral de extração com solventes de diferentes polaridades, assim como a hidrólise do extrato aquoso e a otimização da extração via carvão ativado e utrassonicação são apresentados.

PALAVRAS-CHAVE: Achillea millefolium, antifúngica, espectrofotometria.

ABSTRACT: The Achillea millefolium (Asteraceae) is known as mil-folhas, mil-em-rama, erva-decarpinteiro and salvação-do-mundo in the Brazilian folks medicine. The A. millefolium phytoterapic applications come from its anti-inflammatory, antibacterial, antihemorrhagic, antidiarrhoeal, antioxidant, antiedema and wound healing properties. In this work, a phytochemical prospection of A. millefolium, as well a study of the antifungal activity involving Colletotrichum musae and a spectrophotometric study involving extractions using solvents with different polarities were performed. The results of the phytochemical study point the presence of the flavonoids, tannins and coumarins. The antifungal activity was studied, which a reduction around $55 \%$ of the fungus growth was observed. A spectrophotometric study involving spectral profiles, hydrolysis of the aqueous extract and an extraction optimization by active charcoal and ultrasound are presented.

KEYWORDS: Achillea millefolium, antifungal, spectrophotometry. 
osa, M. B. et al./Revista Eletrônica de Farmácia Vol 6(3), 81-93, 2009.

\section{INTRODUÇÃO}

O uso de plantas medicinais no mundo contribui significantemente para os cuidados primários da saúde (HALBERSTEIN, 2005). No Brasil, um grande número de plantas tem sido usado na forma de extratos brutos, infusões ou emplastos para tratar infecções comuns (MORAIS et al., 2005; VENDRUSCOLO et al., 2005; TORRES et al., 2005). Recentemente, muitas plantas medicinais têm se tornado o foco de estudos intensos considerando sua conservação e efeitos farmacológicos. As pesquisas de novos agentes ativos farmacologicamente, através do screening de recursos naturais tais como fermentação microbiana e extratos de plantas têm levado a descoberta de muitos fármacos usados clinicamente (YUE-ZONG, 1998; LEITÃo et al., 2006; FUNKE \& MELZIG, 2006).

O controle de doenças em animais e vegetais com o uso de extratos de plantas medicinais tem sido um desafio. Extratos de plantas apresentam em sua composição substâncias efetivas contra patógenos de plantas e animais e são praticamente inofensivos ao meio ambiente quando comparados com derivados sintéticos, podendo até superar sua ação antimicrobiana (MIGUEL \& MIGUEL, 1999; STANGARLIN et al., 1999). Estudos realizados com extratos brutos e/ou óleos essenciais obtidos a partir de plantas medicinais têm evidenciado o potencial das mesmas no controle de fitopatógenos, tanto por sua ação fungicida direta, inibindo o crescimento micelial e germinação de esporos, quanto pela indução de fitoalexinas (DI STASI, 1996). Estas são metabólitos secundários, antimicrobianos, de baixo peso molecular e produzidas pelas plantas em resposta a estresses físicos, químicos ou biológicos, sendo capazes de impedir ou reduzir a atividade de agentes patogênicos. De forma geral, o modo de ação das fitoalexinas sobre fungos inclui granulação citoplasmática, desorganização dos conteúdos celulares, ruptura da membrana plasmática e inibição de enzimas fúngicas. Esses efeitos refletem-se na inibição da germinação e elongação do tubo germinativo e redução ou inibição do crescimento micelial (LO, et al., 1996; PURKAYASTHA, 1995).

Entretanto estudos mais apurados devem ser realizados com o intuito de garantir a qualidade e eficácia de produtos in natura, visto que a busca da qualidade é um movimento que adquiriu dimensão mundial. Cada vez mais os produtores de bens $\mathrm{e}$ serviços percebem que a qualidade é o componente mais importante para oferecer produtos capazes de satisfazer as necessidades dos usuários. Da mesma forma, os usuários desses bens e serviços requerem cada vez mais o melhor desempenho dos produtos que adquirem. Mediante essa realidade fica claro que o controle de qualidade de fitoterápicos é imprescindível no meio comercial, pois muitas espécies vegetais são vendidas sem quaisquer garantias de qualidade (CARVALHO et al., 2008).

A Achillea millefolium é uma planta da família Asteraceae, nativa da Europa, América do Norte, Sul da Austrália, Ásia e amplamente presente na flora brasileira. É também conhecida como mil-em-rama, milefolio, ervado-carpinteiro (BALBACH, 1993; CANDAN et al., 2003). É uma planta perene com caule duro, possui 30 a $90 \mathrm{~cm}$ de altura, folhas 
osa, M. B. et al./Revista Eletrônica de Farmácia Vol 6(3), 81-93, 2009.

abundantes recortadas e flores de cor rosa ou branca. Tem sido usada principalmente na medicina como antibacteriana, antifúngica, antitumoral, cicatrizante, antioxidante, antiedematosa (ROSA et al., 2008).

O presente estudo objetivou conhecer as principais classes de compostos majoritários presentes em diferentes extratos da Achilleia através de uma prospecção fitoquímica, além de avaliar a atividade antifúngica da planta frente ao fitopatógeno Colletotrichum musae, comum na banana (Musa spp.) e que causa antracnose no fruto, com ampla distribuição geográfica (WARDLAW, 1972). Além disso, um estudo espectrofotométrico visando otimizar a extração da $A$. millefolium usando diferentes solventes com diferentes polaridades e avaliando-se tempos de extração, uso do ultrasom, efeito do $\mathrm{pH}$, entre outros, são apresentados e discutidos no decorrer deste estudo.

\section{MATERIAIS E MÉTODOS}

\section{Material vegetal}

A parte aérea (folha e caule) da $A$. millefolium foi coletada após 100 dias de plantio no Horto Botânico do Campus Antônio Rodrigues Coelho da Universidade Vale do Rio Doce - UNIVALE - Governador Valadares, Minas Gerais. O material coletado foi identificado e autenticado por comparação, onde a espécie testemunho foi depositada (exsicata $n^{\circ} 30.080$ ).

Após a coleta procedeu-se a secagem utilizando uma estufa com temperatura de $40^{\circ} \mathrm{C}$ durante 48 horas. A planta seca foi triturada com o auxílio de um moinho de martelos (Marconi ${ }^{\circledR}$ - Modelo 340). O pulverizado foi armazenado ao abrigo da luz e em sacos de papel pardo.

\section{Prospecção fitoquímica}

Para a prospecção fitoquímica dos extratos aquosos e etanólicos foram produzidos utilizando-se $1,0 \mathrm{~g}$ da planta pulverizada e seca e $50 \mathrm{ml}$ do solvente sob ultrassonicação (Unique $^{\circledR}$ - MaxiClean 1400) por 20 minutos a $28{ }^{\circ} \mathrm{C}$ com a adição de $1,0 \mathrm{~g}$ de carvão ativo para eliminação da clorofila. Após a extração filtrou-se o extrato em papel de filtro com $2 \mu \mathrm{m}$ de porosidade. A prospecção fitoquímica foi realizada com a finalidade de se verificar a presença de classes de compostos majoritários, conforme descrito em SIMÕES et al., 2004. Os testes se baseiam em reações cromáticas e de precipitação (SIMÕES et al., 2004). Neste estudo avaliou-se a presença de açúcares redutores, compostos fenólicos, taninos, flavonóides, cumarinas, compostos antracênicos, heterosídeos cardiotônicos, saponinas, naftoquinonas, antraquinonas, triterpenos e esteróides.

\section{Atividade antifúngica - Colletotrichum musae}

Utilizou-se um isolado do fungo Colletotrichum musae obtido diretamente de bananas doentes contaminadas da região do Vale do Rio Doce, leste de Minas Gerais. O isolamento do patógeno foi realizado no Laboratório de Fitopatologia da Faculdade de Ciências Agrárias da UNIVALE. O fungo foi isolado inicialmente em tubos de ensaios, caracterizado e repicado em placas de Petri contendo meio de cultivo BDA (Batata Dextrose Agar). A metodologia utilizada é baseada na infusão do extrato no meio de cultura onde 
osa, M. B. et al./Revista Eletrônica de Farmácia Vol 6(3), 81-93, 2009.

pesou-se $0,1 \mathrm{~g}$ de extrato seco obtido de uma extração etanólica da $A$. millefolium e dilui-se em $150 \mu \mathrm{l}$ de DMSO (dimetilsulfóxido). O extrato foi então colocado em $40 \mathrm{ml}$ de BDA, homogeneizado e vertido em placas de Petri estéril. Após estabilização do meio, um disco de $8 \mathrm{~mm}$ de micélio com sete dias de repicado foi colocado no centro de cada placa de Petri. Após cinco dias de incubação, o crescimento radial do fungo foi determinado considerandose o diâmetro médio da colônia quantificado em dois sentidos ortogonais com o uso de régua transparente. Os testes foram realizados em triplicata.

\section{Estudo espectrofotométrico}

O estudo espectrofotométrico da $A$. millefolium subdividiu-se em três partes: 1 . obtenção de um perfil espectrofotométrico da extração para solventes com diferentes polaridades; 2. avaliação espectral do efeito do $\mathrm{pH}$ (hidrólise) sobre o extrato aquoso da $A$. millefolium e 3. estudo da influência de carvão ativo na extração de clorofila (mascarante na prospecção fitoquímica).

\section{Perfil espectrofotométrico de extração}

Para a obtenção dos vários extratos brutos foram testados separadamente água, metanol, hexano, éter e diclorometano como solventes. Utilizou-se $1,0 \mathrm{~g}$ do pulverizado em $100 \mathrm{ml}$ de cada solvente sendo ultrassonicados (Unique $^{\circledR}$ - MaxiClean 1400) por 30 minutos. Após esta etapa foram obtidos os espectros medidos de 200 a $700 \mathrm{~nm}$ com intervalos de $2 \mathrm{~nm}$. Um espectrofotômetro Femto 800 XI com cubeta de quartzo de $1 \mathrm{~cm}$ de caminho óptico foi usado para aquisição dos espectros.
2. Hidrólise do extrato aquoso da A. millefolium

Para estudo da hidrólise do extrato aquoso utilizou-se $1,0 \mathrm{~g}$ do pulverizado em 100 $\mathrm{ml}$ de água e levou-se a ultrassonicação por 30 minutos. Foram separadas 3 alíquotas, uma com pH original $(6,0)$, medido com pHmetro Quimis $^{\circledR}-$ Q 400a com eletrodo de vidro calibrado previamente com tampões $\mathrm{pH} 4,0$, 7,0 e 10,0 - Merck. Nas outras duas alíquotas foram adicionados, separadamente, gotas de $1 \mathrm{M} \mathrm{HCl}$ e de $1 \mathrm{M} \mathrm{NaOH}$ reduzindo-se o $\mathrm{pH}$ para 1,0 e elevando-se $0 \mathrm{pH}$ para 14 respectivamente. Os espectros das alíquotas nos valores de $\mathrm{pH} 1,0,6,0$ e 14,0 foram avaliados.

\section{Influência de carvão ativo na extração}

Neste estudo utilizou-se $1,0 \mathrm{~g}$ de $A$. millefolium em $100 \mathrm{ml}$ de metanol e, separadamente, $0,1,0,5$ e $1,0 \mathrm{~g}$ de carvão ativo foram adicionados afim de se avaliar a extração de clorofila e se otimizar um tempo adequado de extração da clorofila. As alíquotas foram ultrassonicadas por 60 minutos, onde alíquotas foram retiradas em intervalos de 10 minutos. Os extratos com carvão foram filtrados e o espetro para cada alíquota foi obtido.

\section{RESULTADOS E DISCUSSÃO}

A prospecção fitoquímica da $A$. millefolium mostrou a presença de metabólitos secundários, os quais apresentam potencialmente propriedades antimicrobianas, como foi o caso dos compostos fenólicos, taninos, flavonóides e cumarinas relatado por COWAN (1999). Açúcares redutores não foram detectados. 
osa, M. B. et al./Revista Eletrônica de Farmácia Vol 6(3), 81-93, 2009.

As plantas são capazes de produzir diferentes substâncias tóxicas em grandes quantidades, como alguns alcalóides, cumarinas e outras provenientes do metabolismo secundário aparentemente justificado para sua própria defesa contra vírus, bactérias, fungos e animais predadores (HAVSTEEN, 2002; SIMÕES et al., 2004). Os compostos produzidos pelos vegetais podem ser agrupados genericamente em dois grupos: os metabólitos primários, tais como carboidratos, aminoácidos e lipídeos e os secundários que são compostos elaborados a partir da síntese dos metabólitos primários, tais como compostos fenólicos, terpenóides, óleos essenciais e alcalóides entre outros (SIMÕES et al., 2004). Esses compostos secundários são, em sua maioria, responsáveis pelos efeitos medicinais, ou tóxicos das plantas, além de apresentarem grande importância ecológica, pois atuam na atração de polinizadores e na ativação da defesa química da planta contra estresse ambiental (BALADRIN et al., 1985; DI STASI, 1996).

Com relação ao estudo da atividade antifúngica utilizando o método da infusão do extrato bruto, foi possível discriminar o efeito do extrato na inibição do crescimento do patógeno medindo-se o diâmetro médio do crescimento radial do fungo em meio BDA. A inibição de $55 \%$ no crescimento micelial foi observado, quando comparado ao controle (meio BDA mais solvente, sem o extrato da $A$. millefolium), o crescimento radial da colônia reduziu de 9,00 para 4,03 cm (Tukey, 5\%). Este resultado indica a potencialidade da atividade fungicida da $A$. millefolium. Portanto, economicamente é muito importante estudar o uso de plantas no combate "orgânico" de fungos em plantas, devido aos seus prejuízos causados por estes, tanto no campo, quanto na pós-colheita, pois se tornam um fator limitante na qualidade e comercialização do produto (JEFFRIES et al., 1990). Desta forma, a busca de novos fungicidas naturais a partir de plantas da flora latino-americana, baseada principalmente no seu uso etnofarmacológico assume papel importante neste contexto (FENNER et al., 2006). A atividade aqui encontrada foi obtida a partir do extrato etanólico bruto, e pode ser potencializada com a identificação de frações mais ativas do mesmo.

Atualmente, em todos os lugares do mundo onde se pratica uma agricultura econômica, a intervenção para o controle de doenças de plantas é largamente realizada através de pesticidas (KIMATI et al., 1997). Sem dúvida, o uso racional desses produtos pode ter, em curto prazo, um efeito positivo para o produtor. No entanto, em longo prazo, além do surgimento de fitopatógenos resistentes às substâncias químicas utilizadas, os resultados para a sociedade como um todo e para o meio ambiente podem se tornar negativos devido à poluição causada pelos resíduos. Nesse contexto, termos como "agricultura alternativa" ou "agricultura sustentável" obtêm expressão política e estimulam a busca por novas medidas de proteção das plantas contra as doenças (ZADOKS, 1992).

A indução de resistência (ou indução de proteção, imunidade adquirida, ou resistência sistêmica adquirida) envolve a ativação de mecanismos de defesa latentes, existentes nas plantas, em resposta ao tratamento com agentes bióticos ou abióticos. Esses mecanismos de resistência induzidos podem 
osa, M. B. et al./Revista Eletrônica de Farmácia Vol 6(3), 81-93, 2009.

ser estruturais, como papila, lignificação e tilose, ou bioquímicos, como o acúmulo de fitoalexinas e de proteínas relacionadas à patogênese (como b-1,3 glucanase e quitinase degradadoras da parede celular de fungos) (PASCHOLATI \& LEITE, 1995; HAMMERSCHMIDT \& DANN, 1997).

Diferentes solventes significam diferentes moléculas ou classes de compostos que podem ser extraídos e que absorvem em diferentes comprimentos de onda ou faixas espectrais. Tomando como exemplo quatro comprimentos de onda aleatórios $(250 \mathrm{~nm}, 340 \mathrm{~nm}, 440 \mathrm{~nm}$, $660 \mathrm{~nm}$ - ver Tabela 1), observa-se uma ordem de extração característica para cada comprimento de onda.

Tabela 1. Ordem de extração de diferentes solventes em 250, 340, 440 e 660nm.

\begin{tabular}{|c|c|}
\hline$\lambda / \mathrm{nm}$ & Solventes (ordem de extração observada) \\
\hline 250 & $\begin{array}{c}\text { hexano }>\text { éter }>\text { água }>\text { metanol }>\text { etanol }> \\
\text { diclorometano }\end{array}$ \\
\hline 340 & $\begin{array}{c}\text { metanol }>\text { água }>\text { etanol }>\text { éter }>\text { diclorometano }> \\
\text { hexano }\end{array}$ \\
\hline 440 & $\begin{array}{c}\text { éter }>\text { metanol }>\text { diclorometano }>\text { etanol }>\text { água }> \\
\text { hexano }\end{array}$ \\
\hline 660 & $\begin{array}{c}\text { éter }>\text { metanol }>\text { diclorometano }>\text { etanol }>\text { água }>> \\
\text { hexano }\end{array}$ \\
\hline
\end{tabular}

Essa diferenciação no perfil espectral de extração mostra as diferentes interações físicoquímicas de cada solvente com as classes de compostos identificadas na prospecção fitoquímica e que podem variar significativamente conforme 0 solvente utilizado. Esses perfis colaboram numa melhor escolha de solvente, bem como numa otimização de uma extração de acordo com a presença de grupos funcionais específicos. Aspectos como a polaridade, presença ou ausência de sistemas $\pi$ (insaturações), de anéis aromáticos, ácidos ou bases de Lewis (espécies ricas ou carentes de pares de elétrons), podem ser identificadas de acordo com a faixa espectral na qual ocorre, ou não, uma transição eletrônica. Portanto, o comprimento de onda remete a dois aspectos básicos e complementares, a polaridade da espécie que está sendo extraída, bem como o comportamento espectral do grupamento frente a diferentes solventes.

Cabe ressaltar que não foi observado neste estudo um melhor solvente quando se trabalha com extrato bruto. O que se observa através da análise espectral é que, de acordo com a necessidade, pode-se usar uma combinação de solventes atrelada à necessidade ou objetivo do estudo.

Outro aspecto importante que cabe ser destacado é que, se tomarmos como exemplo o comprimento de onda de 490nm (Figura 1), observa-se que para quase todos os solventes, exceto para o hexano, que extraiu menos 
osa, M. B. et al./Revista Eletrônica de Farmácia Vol 6(3), 81-93, 2009.

comparativamente, os demais solventes extraíram uniformemente os compostos que absorvem neste comprimento de onda. Esta peculiaridade colabora também na seleção de possíveis comprimentos de onda para posteriores estudos envolvendo, por exemplo, separações cromatográficas. Ou seja, conhecendo-se o perfil espectral de um extrato torna-se possível otimizar as melhores condições de extração de compostos de interesse.

Ao longo da faixa espectral analisada se enquadram compostos fenólicos das classes isoflavonóides e biflavonóides aos quais são atribuídas atividades antifúngicas e absorvem em 240-285 e 300-400, conforme SIMÕES et al. (2004).

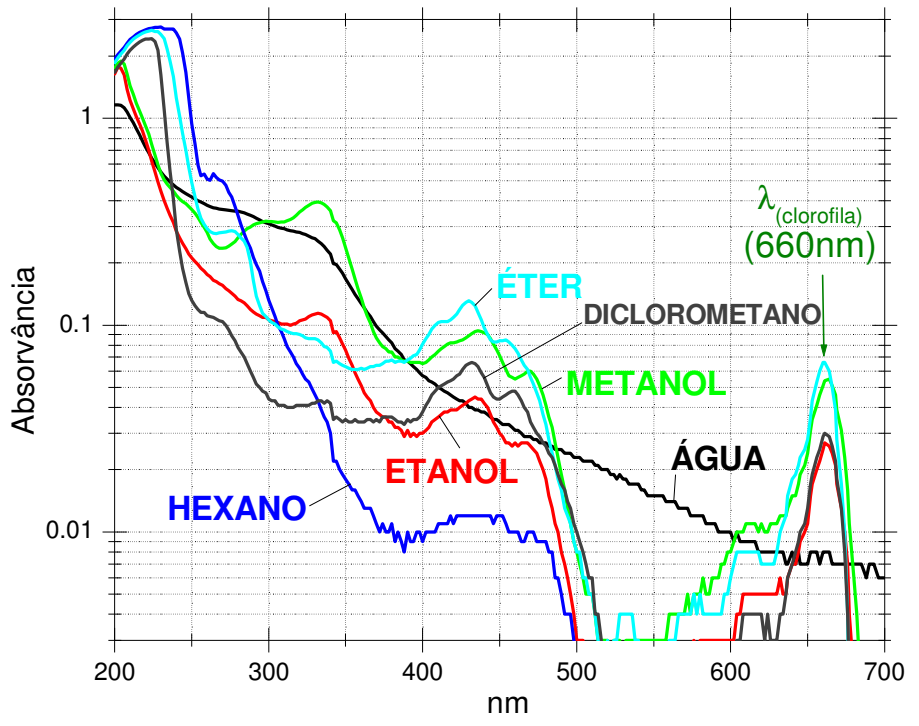

Bandas de intensidade elevada $(\varepsilon=10.000-$ 20.000) para $\lambda>210 \mathrm{~nm}$, podem corresponder a cetonas $\alpha, \beta$-insaturadas, dienos ou polienos. Quão mais extenso for o sistema conjugado maior é o $\lambda_{\text {máx }}$ de absorção. Cetonas, ácidos, ésteres, amidas e outros compostos simples contendo sistemas $\pi$ de elétrons não ligantes produzem bandas de absorção com $\lambda_{\text {máx }}>300 \mathrm{~nm}$ com intensidade baixa e $\lambda_{\text {máx }}<250 \mathrm{~nm}$ com intensidade elevada. Em sistemas conjugados, pode-se observar desvios batocrômicos. Esse desvio pode ser verificado variando-se $0 \mathrm{pH}$ da solução estudada e observada na Figura 2 (EWING, 1972; SKOOG, 2002).

Figura 1. Perfil espectral do extrato bruto da A. millefolium para solventes com diferentes polaridades.
Com relação à influência do $\mathrm{pH}$ sobre o extrato aquoso da A. millefolium (Figura 2), os espectros medidos para valores de $\mathrm{pH}$ entre 1,0 e 6,0 não apresentaram modificações significativas no seu perfil espectral, o que indica pouca ou quase nenhuma hidrólise (deprotonação) em meio ácido e neutro dos constituintes da planta. Observa-se uma mudança significativa no espectro para valores básicos de $\mathrm{pH}$, o que indica uma plausível hidrólise com a deprotonação de grupos funcionais. A formação de pontos isosbésticos ( $\mathrm{pi}_{1}$ e $\mathrm{pi}_{2}$ ) evidenciam uma mudança estrutural das moléculas que constituem o extrato bruto, principalmente no que tange a disponibilidade de pares de elétrons livres, que é maior para valores mais altos de $\mathrm{pH}$. Este estudo embasa etapas posteriores envolvendo separações cromatográficas, pois muitas vezes $\mathrm{opH}$ do eluente utilizado difere do $\mathrm{pH}$ original do extrato e conseqüentemente pode alterar a resposta do detector caso este envolva absorção de luz (lei de Beer), uma vez que uma mudança de $\mathrm{pH}$ de um extrato pode acarretar, como observado, uma mudança significativa (deslocamento) no espectro do extrato.

Como as reações estudadas durante a prospecção fitoquímica envolvem reações de 
osa, M. B. et al./Revista Eletrônica de Farmácia Vol 6(3), 81-93, 2009.

aparecimento ou desaparecimento de cor, ou seja, de revelação cromática como indicativos qualitativos da presença ou ausência de determinadas classes de compostos, a presença da clorofila interfere em certas reações e por isso, é conveniente sua máxima eliminação, de modo que não "sombreie" a resposta dos ensaios fitoquímicos. Além disso, procurou-se otimizar o tempo de extração em função das massas, tanto de carvão, quanto da planta.

Os valores máximos de absorção (absorvâncias) em 660nm foram obtidos de modo que seus valores são apresentados na Figura 4, onde os perfis de extração para as três massas de carvão são apresentados. Observa-se que para a razão $0,1: 1,0$ (massa de carvão:massa de $A$. millefolium) houve

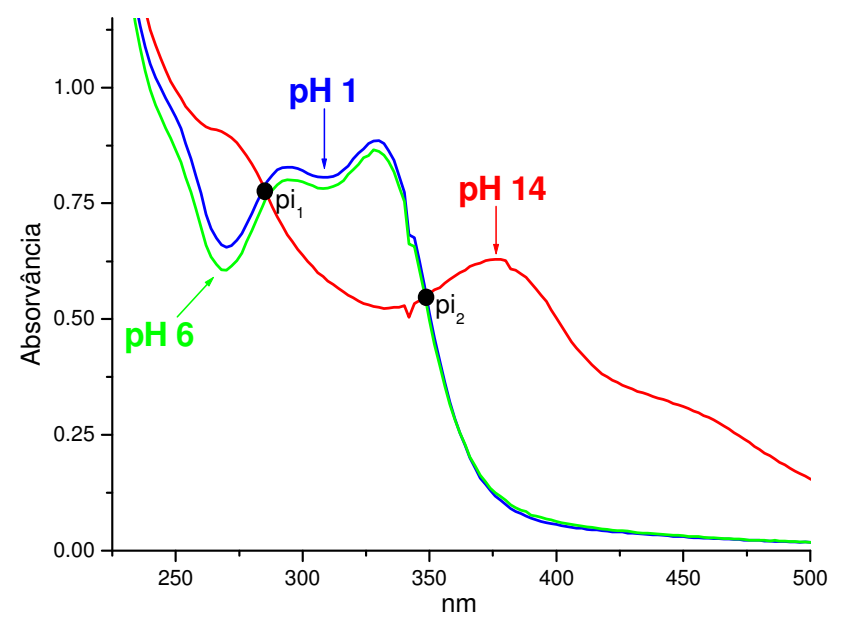

apenas uma redução de $10 \%$ na concentração de clorofila ao longo dos 60 minutos de extração via ultrassonicação. Utilizando-se uma razão de 0,5:1,0 (massa de carvão:massa de A. millefolium) ocorreu uma adsorção de $70 \%$ da clorofila ao longo de 60 minutos de ultrassonicação e por fim, com uma razão $1,0: 1,0$ (massa de carvão:massa de $A$. millefolium), obteu-se uma redução de $90 \%$ da clorofila em apenas 10 minutos de extração, servindo então como condição otimizada para a prospecção fitoquímica. Cabe ressaltar na Figura 4 que o termo [extrato]/[extrato] significa as razões entre as absorvâncias obtida para $660 \mathrm{~nm}$ no tempo zero (denominador) e as demais absorvâncias relativas ao longo da ultrassonicação (numerador).
Figura 2. Perfil espectral do extrato aquoso da $A$. millefolium para diferentes valores de $\mathrm{pH}$. $\left(\mathrm{pi}_{1}\right.$ e $\mathrm{pi}_{2}=$ pontos isosbésticos).

Na Figura 3 estão dispostos os espectros medidos nos tempos 0, 10, 20, 30, 40, 50 e 60 minutos de extração utilizando $0,5 \mathrm{~g}$ de carvão para $1 \mathrm{~g}$ de $A$. millefolium em $100 \mathrm{ml}$ de metanol. 


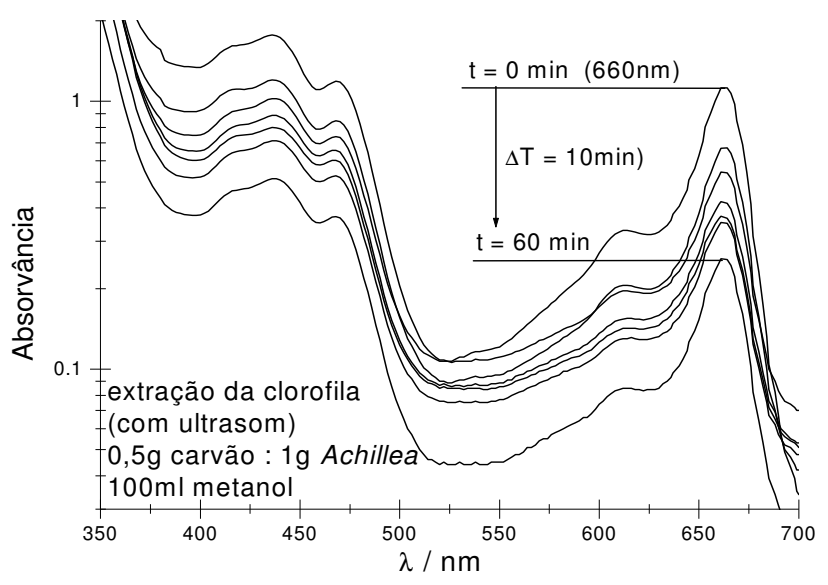

Figura 3. Adsorção da clorofila utilizando-se $0,5 \mathrm{~g}$ de carvão e $1 \mathrm{~g}$ de $A$. millefolium para um extrato metanólico.

\section{CONCLUSÃO}

Uma prospecção fitoquímica para extratos brutos de $A$. millefolium foi otimizada com base num estudo envolvendo ultrassonicação e adsorção de clorofila por carvão ativado. Algumas classes de compostos conhecidos como metabólitos secundários foram detectados positivamente, ratificando sua importância em estudos que procuram diferentes ações das plantas, como a ação antifúngica observada neste estudo.

Ensaios frente ao fungo Colletotrichum musae foram realizados, onde os resultados indicam a potencialidade da $A$. millefolium como inibidora da atividade deste patógeno, uma vez que houve uma redução de mais da metade no seu crescimento micelial. Os resultados deste trabalho ainda podem ser considerados preliminares, pois variáveis ambientais como a sazonalidade da planta e fatores extrínsecos

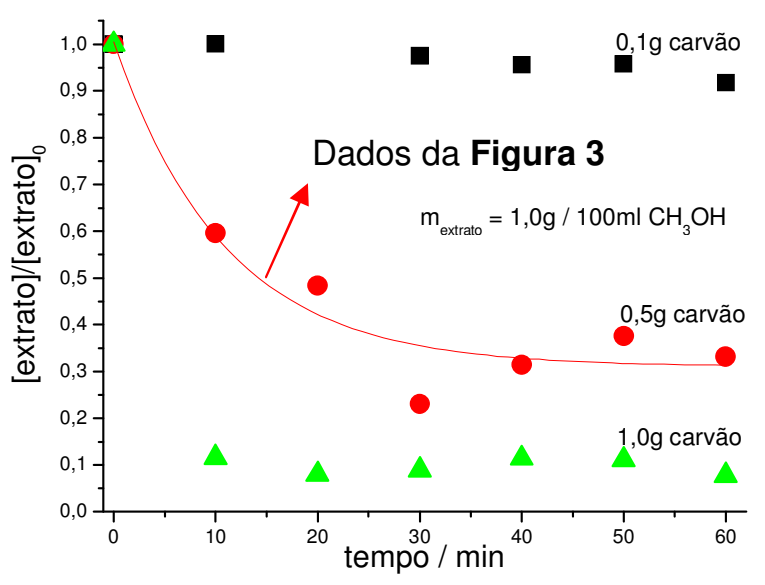

Figura 4. Decaimentos observados para diferentes razões entre $A$. millefolium e carvão ( $0,1 \mathrm{~g}$ carvão $: 1 \mathrm{~g}$ A. millefolium; $0,5 \mathrm{~g}$ carvão: $1 \mathrm{~g}$ A. millefolium e $1 \mathrm{~g}$ carvão : $1 \mathrm{~g} A$. millefolium) e obtidos da Figura 3.

como pluviometria, radiação solar, entre outros, não foram avaliados. Portanto, este trabalho contribui para o aperfeiçoamento da aplicação de $A$. millefolium "in natura", além de promover uma forma alternativa de tratamento frente a este fitopatógeno que ataca frutos como a banana (Musa spp.) que causa antracnose. Assim, este serve também como indicativo de que muitos produtores poderiam utilizar de extratos brutos da $A$. millefolium no controle e/ou prevenção de fungos em frutos.

Para finalizar, no tocante ao uso da espectrofotometria como ferramenta no estudo fitoquímico, ressaltamos sua importância, pois essa pode vir a ser incorporada, tanto no controle de qualidade, bem como na investigação de características espectrais que podem ser muito úteis em trabalhos posteriores que envolvem a elucidação estrutural dos constituintes dos extratos brutos das plantas.

\section{AGRADECIMENTOS}

Os autores agradecem à FAPEMIG (CAG-1985/05) pelo suporte financeiro. 
osa, M. B. et al./Revista Eletrônica de Farmácia Vol 6(3), 81-93, 2009.

\section{REFERÊNCIAS BIBLIOGRÁFICAS}

BALANDRIN, M.F.; KLOCKE, J.A.; WURTELE, E.S.; BOLLINGER, W.H. Natural plant chemicals: source of industrial and medicinal materials. Science, v.228, n.4304, p.1054-1060, 1985.

BALBACH, A. As Plantas Curam. 2.ed. Itaquaquecetuba: Vida Plena, 1993.

CANDAN, F.; UNLU, M.; TEPE, B.; DAFERERA, D.; POLISSIOU, M.; SOKMEN, A.; AKPULAT, H.A. Antioxidant and antimicrobial activity of the essencial oil and methanol extracts of Achillea millefolium subsp. millefolium afan. (Asteraceae). Journal of Ethnopharmacology, v.87, n.2, p.215220, 2003.

CARVALHO, C.A.; SILVA, M.B.; OLIVEIRA, T.G.; LIMA, J.M.; ROSA, M.B. Estudo espectrométrico de diferentes estágios fenológicos da Brassica oleracea var. capitata. Revista Brasileira de Farmacognosia, v.18, n.2, p.249-257, 2008.

COWAN, M.M. Plant products as antimicrobial agents. Clinical Microbiology Reviews, v.12, n.4, p.564-582, 1999.

DI STASI, L.C. Química de produtos naturais: Principais constituintes ativos. In: DI STASI, L.C. (Ed.). Plantas Medicinais: Arte e Ciência - Um guia de estudo interdisciplinar. 1.ed. São Paulo: Editora UNESP, 1996.

EWING, G.W. A absorção de radiação: ultravioleta e visível. São Paulo: Edgard Blücher, 1972.

FENNER, R.; BETTI, A.H.; MENTZ, L.A.; RATES, S.M.K. Plantas utilizadas na medicina popular brasileira com potencial atividade antifúngica. Revista Brasileira de Ciências Farmacêuticas, v.42, n.3, p.369-394, 2006.

FUNKE, I; MELZIG, M.F. Traditionally usad plants in diabetes therapy - phytotherapeutics as inhibitors of a-amylase activity. Revista Brasileira de Farmacognosia, v.16, n.1, p.1-5. 2006.

HALBERSTEIN, R.A. Medicinal plants: historical and cross-cultural usage patterns. Annals of Epidemiology, v.15, n.9, p.686-699, 2005.

HAMMERSCHMIDT, D.; DANN, E.K. Induced resistance to disease. In: RECHCIGL, N.A.; RECHCIGL, J.E. (Ed.). Environmentally Safe Approaches to Crop Disease Control. Boca Raton: Lewis Publishers, 1997. 
osa, M. B. et al./Revista Eletrônica de Farmácia Vol 6(3), 81-93, 2009.

HAVSTEEN, B.H. The biochemistry and medical significance of the flavonoids. Pharmacology and Therapeutics, v.96, n.2, p.67-202, 2002.

JEFFries, P. DODD, J.C.; JEGERAND, M.J.; PLUMBLEY, R.A. The biology and control of Colletotrichum species on tropical fruits crops. Plant Pathology, v.39, n.3, p.343-366, 1990.

KIMATI, H.; GIMENEZ-FERNANDES, N.; SOAVE, J.; KUROZAWA, C.; NETO, F. B.; BETTIOL, W. Guia de Fungicidas Agrícolas - Recomendações por Cultura. 2.ed. Jaboticabal: Grupo Paulista de Fitopatologia, 1997.

LEITÃO, S.G.; CASTRO, O.; FONSECA, E.M.; JULIÃO, L.S.; TAVARES, E.S.; LEO, R.R.T.; VIEIRA, R.C.; OLIVEIRA, D.R.; LEITÃO, G.G.; MARTINO, V.; SULSEN, V.; BARBOSA, Y.A.G.; PINHEIRO, D.P.G.; SILVA, P.E.A.; TEIXEIRA, D.F.; LOURENÇO, M.C.S. Screening of Central and South American plant extracts for antimycobacterial activity by the Alamar Blue test. Revista Brasileira de Farmacognosia, v.16, n.1, p.6-11, 2006.

LO, S.C.; WEIERGANG, I.; BONHAM, C.; HIPSKIND, J.; WOOD, K.; NICHOLSON, R.L.; Phytoalexin accumulation in sorghum: identification of a methyl ether of luteolinidin. Physiological and Molecular Plant Pathology, v.49, n.1, p.21-31, 1996.

MIGUEL, M.D.; MIGUEL, G.O. Desenvolvimento de fitoterápicos. São Paulo: Robe, 1999.

MORAIS, S.M.; DANTAS, J.D.P.; SILVA, A.R.A.; MAGALHAES, E.F. Plantas medicinais usadas pelos índios Tapebas no Ceará. Revista Brasileira de Farmacognosia, v.15, n.2, p.169-177, 2005.

PASCHOLATI, S.F.; LEITE, B. Hospedeiro: mecanismos de resistência. In: BERGAMIN FILHO, A.; KIMATI, H.; AMORIM, L. (Ed.). Manual de Fitopatologia - Princípios e Conceitos. São Paulo: Ed. Agronômica Ceres, v.1, 1995.

PURKAYASTHA, R.P. Progress in phytoalexin research during the past 50 years. In: DANIEL, M.; PURKAYASTHA, R.P. (Ed.). Handbook of Phytoalexin Metabolism and Action. New York: Marcel Dekker, 1995.

ROSA, M.B.; OliveirA, T.G.; CARVAlHO, C.A.; CARVALHO, L.M.; PEReS, R.L. Estudo espectrofotométrico da atividade fotoprotetora de extratos aquosos de Achillea millefolium, Brassica oleracea var. capitata, Cyperus rotundus, Plectranthus barbatus, Porophyllum ruderale (JACQ.) cass e Sonchus oleraceus. Revista Eletrônica de Farmácia, v.5, n.1, p.101-110, 2008.

SIMÕES, C.O. Farmacognosia da Planta ao Medicamento. 5.ed. Porto Alegre: Editora UFRGS, 2004. 
osa, M. B. et al./Revista Eletrônica de Farmácia Vol 6(3), 81-93, 2009.

SKOOG; D.A.; Aplicações de Espectrometria de Absorção Molecular no Ultravileta/Visível. In: SKOOG; D.A.; HOLLER, F.J.; NIEMAN, T.A. (Ed.). Princípios de análise instrumental. 5.ed. Porto Alegre: Bookman, 2002.

STANGARLIN, J.R.; SCHWAN-ESTRADA, K.R.F.; CRUZ, M.E.S.; NOZAKI, M.H. Plantas medicinais e controle alternativo de fitopatógenos. Biotecnologia, Ciência e Desenvolvimento, v.11, n.11, p.1621, 1999.

TORRES, A.R.; OLIVEIRAI, R.A.G.; DINIZ, M.F.F.M.; ARAÚJO, E.C. Estudo sobre o uso de plantas medicinais em crianças hospitalizadas da cidade de João Pessoa: riscos e benefícios. Revista Brasileira de Farmacognosia, v.15, n.4, p.373-380, 2005.

VENDRUSCOLO, G.S; RATES, S.M.K; MENTZ, L.A. Dados químicos e farmacológicos sobre as plantas utilizadas como medicinais pela comunidade do bairro Ponta Grossa, Porto Alegre, Rio Grande do Sul. Revista Brasileira de Farmacognosia, v.15, n.4, p.361-372, 2005.

WARDLAW, C. W. Diseases of the banana and of the Manila hemp plant. London: MacMillan and Company, 1972.

YUE-ZHONG, S. Recent natural products based drug development: A pharmaceutical industry perspective. Journal of Natural Products, v.61, n.8, p.1053-1071, 1998.

ZADOKS, J.C. The costs of change in plant protection. Journal of Plant Protection, v.9, n.2, p.151159, 1992. 